\title{
Diretrizes de universidades públicas: um estudo sobre regras e comportamento estudantil
}

Victor Henrique Souza Cunha*

Universidade Estadual Paulista Júlio de Mesquita Filho

Raphael Nunes Teixeira** Universidade Estadual Paulista Júlio de Mesquita Filho

Janine Coelho Correa*** Universidade Estadual Paulista Júlio de Mesquita Filho

Kester Carrara****

Universidade Estadual Paulista Júlio de Mesquita Filho

Resumo Estatutos e regimentos são documentos tipicamente utilizados pelas universidades públicas para descrever normas sobre o funcionamento do sistema acadêmico em vários âmbitos. Esta pesquisa tratou de identificar, descrever e analisar regras relacionadas ao ensino na graduação no Estatuto e no Regimento da Universidade Estadual Paulista "Júlio de Mesquita Filho", visando estudo da efetividade, qualidade descritiva e função dessas normas. Este se fundamenta no referencial teórico da Análise do Comportamento, utilizando a contingência de três termos como unidade de análise. A partir da seleção de termos (antecedentes, respostas e consequências) entre as normas do tema pesquisado, foram identificadas e analisadas 15 contingências, 8 incompletas e 7 completas. Estas foram agrupadas em cerimoniais, tecnológicas, positivas e negativas. Identificaram-se, também, categorias às quais as contingências se referem e a distribuição de contingências completas e incompletas nestas: princípios e diretrizes; deveres do estudante; entrada na graduação; representação discente; currículo e calendário; órgãos colegiados. Dos resultados conclui-se que as regras (comportamentais) aplicadas à dimensão educacional no planejamento do ensino superior na universidade estudada poderiam ser mais claras, efetivas e mais democráticas em suas prescrições. O método utilizado também se mostra viável para descrição e análise de prescrições, indicando alterações úteis para o planejamento da formação de estudantes e organização do contexto acadêmico em diversos âmbitos.

PALAVRAS-CHAVE: Diretrizes normativas; Educação superior; Behaviorismo. 
Public universities' guidelines: study on rules and student behavior

Abstract Statutes and regiments are normative texts typically used by public universities to set rules on the functioning of the academic system in various areas. This research intended to identify, describe and analyze rules related to undergraduate teaching in the Statutes and the Regiment of the São Paulo State University, aiming to study the effectiveness, descriptive quality and the function of the norms. This analysis is based on the theoretical approach of Behavior analysis, using the Three-Term Contingency as unit of analysis. From the selection of terms (antecedents, responses and consequences) among the norms related to the main subject, 15 contingencies were identified and analyzed, 8 of them incomplete and 7 complete. These were grouped into ceremonial, technological, positive, and negative. We also identified themes to which the contingencies refers to, and the distribution of complete and incomplete contingencies among then: Principles and guidelines; student duties; higher education entry; administrative bodies; curriculum and calendar; collegiate bodies. The results shows how educational (behavioral) rules identified, which composes the educational planning of the studied university, applied to the educational dimension, could be more clear, effective and more democratic in their prescriptions. Results also show that the method used is feasible for describing and analyzing prescriptions, indicating changes that are useful for the designing students' educational processes and the organization of the academic context in several areas.

KEYWORDS: Normative guidelines; Higher education; Behaviorism.

\section{Introdução}

A universidade focalizada nesta pesquisa, Universidade Estadual Paulista "Júlio De Mesquita Filho", Unesp, é uma das maiores universidades brasileiras, com atuação ampla no Estado de São Paulo e com expressiva participação no ensino, pesquisa e extensão nacionais. Foi criada em 1976 mediante a reunião de diversos institutos de ensino superior isolados do Estado; possui atualmente 34 unidades em 24 cidades, sendo 22 no interior, uma na Capital e uma em São Vicente, litoral paulista. Essa universidade possui 155 cursos de graduação, 37 mil alunos e forma por ano cerca de 5,5 mil novos profissionais (UNESP, 2016). Os documentos maiores que a regem são seu Estatuto (UNESP, 1989) e seu Regimento (UNESP, 1977), que contêm as normas sobre diversos aspectos da vida acadêmica, desde princípios e diretrizes gerais até a descrição de estruturas administrativas e organizacionais.

A literatura revela que alguns trabalhos de interpretação e análise de textos legislativos, normativos em geral, já foram realizados, em especial utilizando a Análise do Comportamento como modelo teórico e metodológico: Cabral (2007) analisou o Estatuto da Pessoa com Deficiência, verificando a consistência da garantia dos direitos de pessoas com deficiência; Lourencetti (2015) visou descrever e analisar os compor- 
tamentos presentes nas legislações referentes à mobilidade urbana na cidade de Bauru. Todorov et al. (2004) analisaram o Estatuto da Criança e do Adolescente (ECA) para identificação das contingências de proteção de crianças e adolescentes como prática cultural. Mas ainda existem poucos estudos que articulam (1) o comportamento descrito por regras, numa perspectiva comportamental, e (2) processos educacionais, particularmente no ensino superior. Um relevante trabalho nessa perspectiva é o de Dantas e Teixeira Júnior (2014) que estudaram regras na Resolução No 214 da Universidade Federal de Mato Grosso do Sul (UFMS), referente às normas de ensino na graduação e possíveis efeitos nos comportamentos dos alunos e professores de Psicologia da instituição.

A Análise do Comportamento é uma abordagem na Psicologia que tem como principal objeto de estudo o comportamento dos organismos nas suas relações com o ambiente (Skinner, 2003). Para Skinner (1984), uma adequada descrição do comportamento dos organismos requer a identificação de eventos contingentes que mantêm relações funcionais. A contingência de três termos é a unidade de análise que permite realizar a descrição desses comportamentos em suas relações, evidenciando o nexo de dependência que o termo antecedente (ocasião e situação na qual ocorre uma determinada resposta), a resposta (ação do organismo) e as consequências que são produzidas por essa resposta. A contingência é a unidade conceitual que descreve as relações entre essas três instâncias: contexto antecedente, respostas e consequências.

Essa noção de uma resposta/comportamento que produz uma alteração no ambiente, que por sua vez afeta a reposta novamente de maneira a aumentar ou diminuir a probabilidade de sua ocorrência em situações similares no futuro, é central para o entendimento do conceito de "comportamento operante". Skinner o define como comportamento no qual o organismo: "opera sobre o ambiente para gerar consequências” (SKINNER, 2003, p.71). O processo de generalização amplia ainda mais essa capacidade na medida em que não só essa resposta específica pode ter ocorrência mais provável a depender da consequência, mas também outras respostas que pertencem a uma mesma classe funcional.

As consequências que podem aumentar ou diminuir a probabilidade de ocorrência das respostas são de dois tipos: reforçadoras ou punitivas (SIDMAN, 2009; SKINNER, 2003). O reforço que caracteriza a consequência pode ser de dois tipos, positivo (no caso em que um estímulo "apetitivo" é adicionado como produto da resposta) ou negativo (no caso em que um estímulo "aversivo" é retirado como produto da resposta). A punição é um procedimento que consiste na retirada de um estímulo apetitivo ou inserção de um estímulo aversivo, que tem como efeito a diminuição da probabilidade de ocorrência da resposta.

Dessa maneira, pode-se identificar e descrever o comportamento dos organismos em diversos contextos e ambientes. O comportamento dos sujeitos num ambiente social pode também ser entendido por meio dessa unidade de análise, a contingência de três termos. Entende-se por comportamento social a interação entre duas ou mais pessoas, uma em relação à outra ou, em conjunto, em relação a um ambiente comum (SKINNER, 2003). 
As respostas, no âmbito operante, não são meramente determinadas pelo antecedente, em uma relação temporal linear. Para Skinner, os comportamentos são multideterminados e dependem de uma história de reforçamento. O comportamento resulta da interação complementar entre três níveis de seleção e variação do comportamento: o filogenético, o ontogenético e o cultural (SKINNER, 1981). Uma explicação fundamentada em somente um desses níveis não é suficientemente adequada.

As contingências analisadas sob a perspectiva de uma dimensão cultural são mantidas por ambientes sociais (SKINNER, 2009), ou seja, sua seleção se deve às consequências sociais para os indivíduos quando se comportam em grupo. Na medida em que as práticas culturais possuem utilidade para os membros de um determinado grupo, elas são mantidas e transmitidas para as futuras gerações (DITTRICH, 2004, 2008; SKINNER, 1981).

Os indivíduos que compõem um determinado grupo controlam os comportamentos dos membros por meio do reforçamento, ou seja, aumentando ou diminuindo a probabilidade de ocorrência de comportamentos por meio de consequências punitivas ou reforçadoras (SKINNER, 2003), esse controle se manifesta na seleção de práticas consideradas "certas" e "erradas". Em grupos, é comum que nem todos os membros participem do planejamento das contingências de reforçamento; é possível que existam membros específicos no grupo que realizem essa tarefa de maneira mais organizada. Esses sujeitos podem constituir o que Skinner chamou de agências de controle (SKINNER, 2003), como por exemplo a Economia, Educação, Governo, Religião e Psicoterapia. Essas agências possuem a tarefa de manipular variáveis e favorecer ou não a prática de determinados comportamentos.

As leis são maneiras de se exercer controle sobre o "comportamento de grupos", classificando, por exemplo, alguns comportamentos como "legais" ou "ilegais", ou passíveis de punição ou reforçamento. A lei pode ser a descrição de uma contingência que define o comportamento dos sujeitos, com um antecedente, uma resposta e uma consequência. As leis, enquanto regras, podem ser entendidas, tipicamente, como a explicitação sistemática de um estímulo antecedente, discriminativo, que serve de ocasião para a resposta de um sujeito e que pode implicar consequências descritas pela própria lei e até fornecidas pela própria agência de controle (ALBUQUERQUE; MESCOUTO; PARACAMPO, 2011; BAUM, 2006; MATOS, 2001; PARACAMPO; ALBUQUERQUE, 2005; SKINNER, 1984).

Baum (2006), descreve um tipo específico de comportamento, os comportamentos controlados por regras, que seriam estímulos discriminativos verbais que controlam um determinado comportamento, assim como no caso das leis ou normativas como as mencionadas nesta pesquisa. Nesse sentido, é possível entender o comportamento controlado pelas leis como um comportamento controlado por regras, de maneira que os sujeitos se comportam pela norma como uma espécie de formulação descritiva de contingências prováveis para uma dada situação. Ou seja, nesse caso as pessoas são expostas a regras que descrevem contingências, mas não diretamente às próprias contingências. Eis que os sujeitos podem agir da maneira como descreve uma determinada lei sem necessariamente ter tido experiência pessoal com as con- 
sequências relacionadas ao seguimento dela; embora a regra somente descreva uma contingência provável para uma dada situação. Disso decorre que a mera existência de regras não é condição possível ou suficiente para controle do comportamento, sendo requerido, adicionalmente, um pareamento entre contingências e os termos ou condições implícitas nas regras, uma sensibilização às consequências desta, para que a regra produza efeito.

As leis podem ser úteis em várias situações, como, por exemplo, afirma Matos (2001), pois as regras podem estabelecer consequências em longo prazo e, ao exercerem controle sobre o comportamento dos sujeitos, tiram a exclusividade de controle comportamental das consequências de curto prazo, que muitas vezes concorrem com as descritas pelas leis.

Souza e Carrara (2013) apresentam um exemplo:

"O indivíduo é reforçado, no curto prazo, pelo alto consumo de alimentos pouco saudáveis, porém, no longo prazo, apresenta problemas de saúde, como aumento nos níveis de colesterol, com riscos para o sistema vascular" (p. 86).

No caso da existência de uma lei que concorresse com esse tipo de reforçamento, e que exercesse controle sobre o comportamento desse indivíduo, por exemplo uma regra moral acerca do benefício de uma alimentação saudável, poderia ser efetiva não só para o indivíduo mas para o grupo, apresentando reforçadores arbitrários como elogio de colegas e professores, dentre outros.

As leis, nessa perspectiva, seriam formulações verbais que podem ser mais bem compreendidas e mais eficazes quando descrevem ações a serem realizadas, em um determinado contexto, e com consequências para seu cumprimento ou não; é, tipicamente, representativa de um planejamento de contingências para controle do comportamento de um determinado grupo (CABRAL; 2007).

Para que uma lei seja efetivamente cumprida é importante que o comportamento a ser ou não seguido seja especificado, assim como as consequências que a execução da lei produziria (ALBUQUERQUE; PARACAMPO, 2010). Não são somente tais fatores que possibilitam que uma lei seja eficiente; o tipo de consequência estipulada também é um fator importante: em casos em que a consequência é punitiva, o sujeito pode vir a apresentar comportamento de esquiva, ou seja, ele pode atrasar ou evitar o contato com a punição, quando esta não está no presente ambiente, e uma vez emitindo o comportamento de esquiva faz com que a punição demore a aparecer, ou acabe nem sequer aparecendo (MOREIRA; MEDEIROS, 2007). Tanto a má descrição de uma lei quanto a possibilidade de um comportamento de esquiva aumentam a probabilidade de que essas leis possam ser "burladas".

Uma vez que o comportamento governado por regras é aqui entendido como a explicitação antecedente de condições para a emissão de uma resposta, o que mantém ou não a ocorrência desse comportamento são as consequências dele resultantes para o sujeito que se comporta. $\mathrm{O}$ sujeito pode não entrar em contato com consequências diretas caso siga uma regra; por exemplo, se a regra for "não dirigir embriaga- 
do", podem-se evitar acidentes que forçariam o sujeito a não mais dirigir embriagado; porém, ao seguir a regra ainda existem consequências arbitrárias que são importantes para que o sujeito continue se comportando de tal maneira, como o respeito ou elogio de colegas (ou eventual punição pelo não cumprimento da regra).

De acordo com as considerações conceituais presentes e diante da reconhecida função de leis ou normas como instrumentais para orientar a vida acadêmica nas universidades, o objetivo desta pesquisa consistiu em identificar, descrever e analisar, no Estatuto (UNESP, 1989) e no Regimento (UNESP, 1977) as contingências sobre ensino na graduação, ou que mantêm relação direta com esse tema. Como já mencionado, a Unesp possui um grande número de estudantes e cursos, o que exige a organização dos comportamentos relacionados ao ensino para que essa prática cultural seja efetiva e de grande relevância social. A escolha desses documentos se dá pela facilidade de acesso ao material e ao fato de que os autores pertencem a essa instituição e estão em contato direto com as regras analisadas.

A partir de uma perspectiva comportamental, utilizando como unidade de análise a contingência de três termos, procurou-se, com base no estatuto e regimento da Unesp, identificar contingências relativas ao ensino na graduação. Nisso consiste o objetivo geral deste trabalho. Derivam-se três objetivos específicos:

1. Caracterizar as contingências identificadas como completas ou incompletas;

2. Caracterizar as contingências identificadas como cerimoniais ou tecnológicas;

3. Caracterizar as contingências identificadas como positivas e negativas.

Entendemos que esse trabalho possui relevância científica e social pelo fato de que consiste em uma análise científica dos documentos normativos, que poderia fundamentar um eventual aprimoramento, além do fato de que o resultado deste trabalho pode ser significante para a comunidade acadêmica na explicitação das contingências planejadas para educação dos estudantes na universidade.

\section{Método}

O método utilizado para coleta de dados consistiu em diversas etapas de estudo documental. De início, foi feita a leitura completa do Estatuto e do Regimento; após essa etapa, uma nova leitura foi realizada para cada documento, onde foram selecionados os três termos de contingências de acordo com a seguinte definição baseada nos estudos de Lourencetti (2015) e Todorov et al. (2005): Antecedente - contexto que estabelece a condição ou circunstância para que o comportamento ocorra, ou deveria ocorrer; Resposta - o termo que descreve ou indica, explícita ou implicitamente, as ações prescritas a um indivíduo ou governo enquanto agência de controle; Consequência - são as implicações diretas ou indiretas relacionadas às respostas.

Levou-se em consideração também a definição de Cabral (2007) sobre os 
termos para análise dos documentos normativos, em que o antecedente se refere também à garantia de direitos; e a resposta se refere também aos deveres prescritos aos agentes.

Após identificação dos diversos termos, as contingências foram organizadas em temas específicos, sendo que as contingências que foram possíveis de serem montadas dentro de um tema específico, com todos os termos, foram definidas como completas, enquanto as que careciam de um ou mais termos, com no mínimo 1 termo identificado, foram definidas como contingências incompletas.

Uma vez identificadas as contingências pelos seus termos e temas, prosseguiu-se com suas caracterizações de acordo com os objetivos específicos, utilizando-se as seguintes definições:

As contingências positivas são caracterizadas por “[...] ações esperadas da população [...]” (CABRAL, 2007, p. 61), ou seja, devem indicar uma resposta específica para produção da consequência. No caso de a contingência não especificar resposta dos indivíduos, sendo descrita de maneira genérica, apresentando somente aquilo que não deve ser feito (e.g., "não respeitar membro da comunidade universitária) ela é considerada negativa.

As contingências cerimoniais, a partir de Skinner (2003) e Glenn (1986), contêm consequências arbitrárias, sociais, que derivam de um poder social estabelecido; por exemplo, o poder expresso pela autoridade da agência de controle ou tradição (quando as contingências expressam valores culturais arbitrários como "bons costumes", "ordem" e não descrevem os benefícios desses). Já as tecnológicas possuem consequências não arbitrárias, que são caracterizadas pela utilidade, pelo valor concreto que possuem para o sujeito que se comporta, seja em ações individuais ou em situação de grupo. Nesse contexto conceitual, a ideia de contingências cerimoniais diz respeito ao uso de práticas historicamente estabelecidas como tradição de costumes. Por exemplo, diante de um fiel em dúvida sobre praticar ou não um dos mandamentos da igreja, o pároco ou pastor poderia dizer que ele deve cumprir um tal mandamento porque isso é desejo de um deus superior ou porque isso é o correto segundo a lei da igreja. No mesmo contexto, uma contingência tecnológica não é liberada diante de um comportamento de seguir o mandamento "não roubarás" (por exemplo) porque trata-se de um dos valores da igreja, mas porque fazer algo assim produz um prejuízo aos seus pares, que de algum modo tiveram que trabalhar para conquistar um certo bem. Ainda mais pragmaticamente, e de modo simplificado, pais "tecnológicos" poderiam dizer à criança algo como: "se você atravessar a rua no sinal vermelho, você pode ser atropelada por um veículo, podendo se machucar, cair e até mesmo morrer". Pais "cerimoniais", no limite, poderiam dizer, diante da pergunta da criança que quer saber por que razão deve atravessar a rua no sinal verde e não no vermelho: "porque tem que ser assim!" ou "porque nós estamos mandando!".

Quanto ao cruzamento dessas categorias que podem caracterizar as contingências, pode-se definir contingências tecnológicas positivas como aquelas que descrevem uma resposta esperada a ser emitida, produzindo uma consequência diretamente 
útil e reforçadora ao comportamento (não arbitrariamente definida pela agência de controle); enquanto as tecnológicas negativas, embora impliquem em consequências de tipo semelhante, falham em descrever respostas específicas. As contingências cerimoniais positivas e negativas seguem o mesmo padrão, diferindo no tipo de consequência descrita na contingência, como foi definido. A presente pesquisa identificou no mínimo uma contingência completa de cada um desses 4 tipos, sendo apresentadas nos resultados (tabelas 3 a 6), servindo de exemplos explicativos

Após essa caracterização das contingências, foi feita uma análise quantitativa dos termos das contingências identificadas, de maneira a saber quanto representam, na quantidade de itens dos documentos, do total. Foram contados todos os artigos, parágrafos, alíneas e incisos de ambos os textos, e das contingências selecionadas, por meio da ferramenta de busca do software Microsoft Word. Quando não foi possível utilizar o software, os itens foram contados individualmente durante a leitura do texto, sem auxílio de softwares.

\section{Resultados}

A partir de ambos os documentos, Estatuto e Regimento da Unesp, foram identificadas 75 normas, que se referiam ao tema estudado e poderiam ser organizados na composição de contingências. Por "normas", entende-se aqui qualquer dos seguintes componentes dos documentos: artigos, parágrafos, incisos ou alíneas. Essas normas foram agrupadas nos seguintes termos de uma contingência: 9 antecedentes, 13 respostas e 7 consequências (Tabela 1). Com esses termos, foi possível identificar 15 contingências no total. $\mathrm{O}$ número de normas (75) é baixo em relação ao total, representando somente $6 \%$ das normas analisadas (tabela 2 ).

Tabela 1 - Quantidade de termos selecionados

\begin{tabular}{c|c}
\hline \multicolumn{2}{c}{ Frequências } \\
\hline Antecedentes & $9(31 \%)$ \\
\hline Respostas & $13(45 \%)$ \\
\hline Consequências & $7(24 \%)$ \\
\hline Total & 29 \\
\hline
\end{tabular}

Nota: As porcentagens são aproximadas e estão em relação ao valor total de termos das contingências identificadas.

A tabela 2 apresenta a quantidade de normas (artigos, parágrafos, incisos e alíneas) do Estatuto, do Regimento, ou de ambos; indicando a quantidade dessas normas especificamente nos trechos dos documentos que foram analisados para identificação das contingências. Percebe-se, portanto, que 1136 é o número total de normas nos dois documentos; normas referentes a ensino na graduação, que foram as analisadas, são 75, representando 6\% do total (Estatuto e Regimento). 46 (61\%) das normas analisadas estão no regimento, embora o Estatuto contenha no total mais normas que o regimento (736 no Estatuto e 400 no regimento). 
Tabela 2 - Quantidade de normas

\begin{tabular}{|c|c|c|c|c|c|}
\hline & Artigos & Parágrafos & Incisos & Alíneas & Total \\
\hline Estatuto & $\begin{array}{c}137(52 \% \text { do } \\
E+R)\end{array}$ & $\begin{array}{c}129(64 \% \text { do } \\
\mathrm{E}+\mathrm{R})\end{array}$ & $\begin{array}{c}363(64 \% \text { do } \\
\mathrm{E}+\mathrm{R})\end{array}$ & $\begin{array}{c}107(100 \% \text { do } \\
\text { E+R) }\end{array}$ & $\begin{array}{c}736(65 \% \\
\text { do E+R) }\end{array}$ \\
\hline Regimento & $\begin{array}{c}127 \text { (48\% do } \\
\mathrm{E}+\mathrm{R})\end{array}$ & $\begin{array}{c}73 \text { (36\% do } \\
\mathrm{E}+\mathrm{R})\end{array}$ & $\begin{array}{c}200(36 \% \text { do } \\
\text { E+R) }\end{array}$ & $\begin{array}{c}0(0 \% \text { do } \\
\text { E+R) }\end{array}$ & $\begin{array}{c}400(35 \% \\
\text { do } E+R)\end{array}$ \\
\hline $\begin{array}{l}\text { Estatuto e } \\
\text { regimento } \\
(\mathrm{E}+\mathrm{R})\end{array}$ & 264 & 202 & 563 & 107 & 1136 \\
\hline $\begin{array}{c}\text { Normas do } \\
\text { Estatuto } \\
\text { analisadas }\end{array}$ & $\begin{array}{c}11 \text { (39\% das } \\
\text { NTA) }\end{array}$ & $\begin{array}{c}1 \text { (14\% das } \\
\text { NTA) }\end{array}$ & $\begin{array}{c}13 \text { (36\% das } \\
\text { NTA) }\end{array}$ & $\begin{array}{c}4(100 \% \text { das } \\
\text { NTA })\end{array}$ & $\begin{array}{c}29(39 \% \\
\text { das NTA) }\end{array}$ \\
\hline $\begin{array}{l}\text { Normas do } \\
\text { Regimento } \\
\text { analisadas }\end{array}$ & $\begin{array}{c}17 \text { (61\% das } \\
\text { NTA) }\end{array}$ & $\begin{array}{c}6 \text { (86\% das } \\
\text { NTA) }\end{array}$ & $\begin{array}{c}23 \text { (64\% das } \\
\text { NTA) }\end{array}$ & $\begin{array}{l}0 \text { (0\% das } \\
\text { NTA) }\end{array}$ & $\begin{array}{c}46(61 \% \\
\text { das NTA) }\end{array}$ \\
\hline $\begin{array}{c}\text { Normas } \\
\text { totais } \\
\text { analisadas }\end{array}$ & $\begin{array}{c}28(11 \% \text { do } \\
\text { E+R) }\end{array}$ & $\begin{array}{c}7(3,4 \% \text { do } \\
E+R)\end{array}$ & $\begin{array}{c}36(6,4 \% \text { do } \\
\text { E+R) }\end{array}$ & $\begin{array}{c}4(3,7 \% \text { do } \\
E+R)\end{array}$ & $\begin{array}{c}75 \text { (6\% do } \\
\mathrm{E}+\mathrm{R})\end{array}$ \\
\hline
\end{tabular}

Nota: As porcentagens são aproximadas.

Abreviações: E, Estatuto; R, regimento; E+R, Estatuto + Regimento; NTA, normas totais analisadas.

Das 15 contingências no total, 7 são completas e 8 incompletas. Entre as completas, 5 são positivas e 2 negativas; 5 cerimoniais e duas tecnológicas. Fazendo cruzamento entre essas categorias, temos 4 contingências cerimoniais positivas, 1 cerimonial negativa, 1 tecnológica positiva e 1 tecnológica negativa. Segue um exemplo de cada:

Tabela 3 - Exemplo de contingência tecnológica positiva

\begin{tabular}{|c|c|c|}
\hline Antecedente & Resposta & Consequência \\
\hline $\begin{array}{l}\text { Artigo } 3^{o} \text { - A organiza- } \\
\text { ção da Unesp obedece } \\
\text { às seguintes diretrizes: } \\
\text { I - Universalidade do } \\
\text { conhecimento; } \\
\text { IV - Indissociabilidade } \\
\text { entre ensino, pesquisa e } \\
\text { extensão; }\end{array}$ & $\begin{array}{l}\text { Artigo 2o - A Unesp [...] Devendo: } \\
\text { I - Criar, preservar, organizar e transmitir o sa- } \\
\text { ber e a cultura por meio do ensino, da pesquisa } \\
\text { e da extensão; } \\
\text { II - Oferecer ensino público, gratuito e de } \\
\text { qualidade, sem discriminação de qualquer na- } \\
\text { tureza; } \\
\text { III - formar cidadãos capacitados para o exer- } \\
\text { cício da investigação e das diferentes profis- } \\
\text { sões; } \\
\text { IV - Privilegiar e estimular a atividade intelec- } \\
\text { tual e a reflexão continuada sobre a sociedade } \\
\text { brasileira, defendendo e promovendo a cidada- } \\
\text { nia, os direitos humanos e a justiça social; } \\
\text { V - Promover atividades de extensão e de arti- } \\
\text { culação com a comunidade. }\end{array}$ & $\begin{array}{l}\text { Artigo } 62 \text { - Os cur- } \\
\text { sos de graduação } \\
\text { habilitarão ao exer- } \\
\text { cício profissional, na } \\
\text { área definida pelo } \\
\text { respectivo currículo. }\end{array}$ \\
\hline
\end{tabular}


Tabela 4 - Exemplo de contingência Tecnológica negativa

\begin{tabular}{|c|c|c|}
\hline Antecedente & Resposta & Consequência \\
\hline $\begin{array}{l}\text { Artigo } 3^{o} \text { - A organização da } \\
\text { Unesp obedece às seguintes } \\
\text { diretrizes: } \\
\text { I - Universalidade do conhe- } \\
\text { cimento; } \\
\text { IV - Indissociabilidade entre } \\
\text { ensino, pesquisa e extensão; }\end{array}$ & $\begin{array}{l}\text { Artigo } 63 \text { - Os cursos de } \\
\text { graduação constituem a ati- } \\
\text { vidade básica da Universida- } \\
\text { de e habilitarão ao exercício } \\
\text { profissional na área definida } \\
\text { pelo respectivo currículo. }\end{array}$ & $\begin{array}{l}\text { Artigo } 62 \text { - Os cursos de gra- } \\
\text { duação habilitarão ao exercí- } \\
\text { cio profissional, na área defi- } \\
\text { nida pelo respectivo currículo. }\end{array}$ \\
\hline
\end{tabular}

Tabela 5 - Exemplo de contingência cerimonial positiva

\begin{tabular}{|c|c|c|}
\hline Antecedente & Resposta & Consequência \\
\hline $\begin{array}{l}\text { Artigo } 90 \text { - A Unesp terá } \\
\text { alunos regulares, alunos espe- } \\
\text { ciais e alunos ouvintes. } \\
\S 20 \text { - Especiais são os alunos } \\
\text { matriculados, com direito a } \\
\text { certificado após o cumpri- } \\
\text { mento dos requisitos míni- } \\
\text { mos. }\end{array}$ & $\begin{array}{l}\text { Artigo } 78 \text { - É obrigatório o } \\
\text { comparecimento do aluno a } \\
\text { todas as atividades escolares } \\
\text { programadas. }\end{array}$ & $\begin{array}{l}\text { Artigo 78. } \S 3^{\circ}-\mathrm{O} \text { aluno } \\
\text { que não tiver frequentado } \\
\text { pelo menos setenta por } \\
\text { cento das atividades esco- } \\
\text { lares programadas estará } \\
\text { automaticamente repro- } \\
\text { vado. }\end{array}$ \\
\hline
\end{tabular}

Tabela 6 - Exemplo de contingência cerimonial negativa

\begin{tabular}{|c|c|c|}
\hline Antecedente & Resposta & Consequência \\
\hline $\begin{array}{l}\text { Artigo } 156 \text { - O regime disci- } \\
\text { plinar visa a assegurar, manter } \\
\text { e preservar a boa ordem, o } \\
\text { respeito, os bons costumes e } \\
\text { os preceitos morais, de forma } \\
\text { a garantir a harmônica convi- } \\
\text { vência entre os membros da } \\
\text { Universidade e a disciplina } \\
\text { indispensável às atividades } \\
\text { universitárias. }\end{array}$ & $\begin{array}{l}\text { Artigo } 161 \text { - Constituem in- } \\
\text { frações disciplinares do corpo } \\
\text { discente: } \\
\text { IV - praticar ato atentatório à } \\
\text { integridade física e moral de } \\
\text { pessoas ou aos bons costumes; } \\
\text { VII - perturbar os trabalhos es- } \\
\text { colares, as atividades científicas } \\
\text { ou o bom funcionamento da } \\
\text { administração; } \\
\text { X - desacatar membro da co- } \\
\text { munidade universitária; }\end{array}$ & $\begin{array}{l}\text { Artigo } 162 \text { - As penas } \\
\text { disciplinares aplicáveis aos } \\
\text { membros do corpo discen- } \\
\text { te são: } \\
\text { I - advertência verbal; } \\
\text { II - repreensão; } \\
\text { III - suspensão; } \\
\text { IV - desligamento }\end{array}$ \\
\hline
\end{tabular}


Quanto às contingências incompletas, elas não foram caracterizadas em positivas/negativas, cerimoniais/tecnológicas, por conta da ausência de termos que seriam necessárias para caracterizá-las como tal.

O gráfico 1 mostra os temas nos quais as contingências foram agrupadas, e o número de contingências agrupadas nesse tema, que são: Princípios e diretrizes (quatro contingências), Deveres do estudante (três contingências), Entrada na graduação (uma contingência); Representação discente (uma contingência); Currículo e calendário (quatro contingências) e Órgãos colegiados (duas contingências).

Gráfico 1 - Contingências por tema

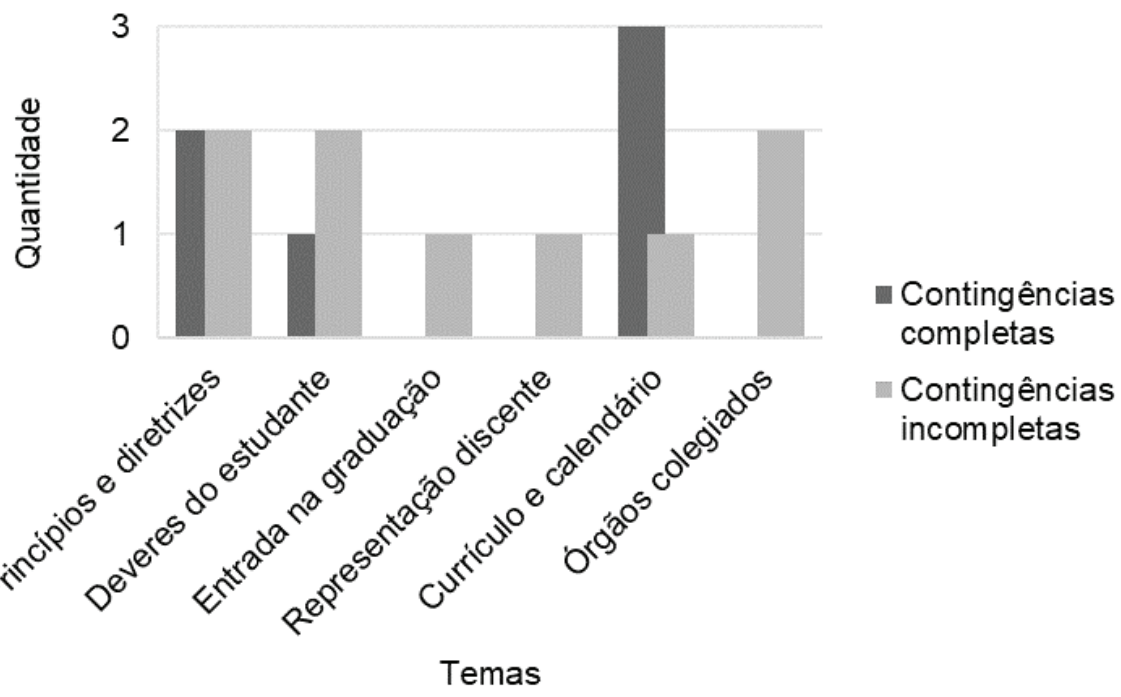

Foram diversos os temas identificados, porém, percebe-se que poucos possuem contingências completas senão o tema "Currículo e calendário", que tem 3 contingências completas, das 4 no total. Os outros três temas carecem completamente de contingências completas, como "Entrada na graduação, Representação discente e Órgãos colegiados. Os temas, apesar de claramente identificáveis, são pouco descritivos.

\section{Discussão}

O número pequeno de contingências pode ser explicado pelo número pequeno de normas referentes ao ensino na graduação, como revela o baixo valor de termos da unidade de contingência selecionados no conjunto dos dois documentos. O valor de $6 \%$ do total de itens selecionados para montar as contingências (Tabela 2) revela que o material existente no estatuto e no regimento que se refere diretamente ao ensino na graduação, ou que mantém com esta relação direta, é significativamente menor do que os outros conteúdos. A escassez de legislação sobre o tema implica necessidade de distribuir as normas em outros documentos normativos da universidade, como por exemplo o Manual de Graduação, mas que, no entanto, deixa de possuir o 
mesmo valor prescritivo do Estatuto e Regimento, atendo-se a um caráter mais instrucional que deliberativo ou normativo.

Das normas analisadas, $61 \%$ se encontram no Regimento, o que significa que maior parte do conteúdo que se refere ao ensino na graduação se encontra neste documento e não no Estatuto.

Alguns artigos selecionados são termos em mais de uma contingência, e ocupam posições diferentes, por exemplo, o artigo 162 do Regimento, ocupa tanto a função de consequência, na contingência da tabela 6 , como resposta em uma outra contingência incompleta. Neste último caso é adicionado ao artigo 162, que descreve penas disciplinares, a consequência da não realização de matricula na universidade antes de decorridos 5 anos, caso tenha sofrido pena de desligamento. Essa característica pode ser prejudicial para o planejamento de contingências, indicando que os artigos possuem pouca objetividade e muita amplitude, podendo se referir a diversos contextos de maneira abstrata, o que caracteriza uma organização de contingências pouco indutiva para a identificação, pelos usuários, de um material prescritivo de comportamentos acadêmicos esperados no âmbito da universidade.

O desequilíbrio na quantidade de termos (tabela 1) explica parcialmente a falta de contingências completas. A maior quantidade de respostas seguida de um número baixo de consequências, na maior parte arbitrárias, pode resultar em um texto normativo de baixa efetividade, como argumentaram Todorov et al. (2004) no trabalho com as normas do Estatuto da criança e do adolescente. Os resultados parecem mostrar que o texto carece de consequências que poderiam melhor definir a função das contingências, o que indica ausência parcial de planejamento de comportamentos educativos, no sentido de que se espera que os estudantes, ou a universidade, realizem algumas ações, mas não se define com precisão, ou às vezes nem se define, o contexto no qual elas devem ocorrer, ou as implicações de sua ocorrência.

Além do número maior de contingências incompletas $(53,4 \%)$, é possível notar a partir dos resultados que predominam as contingências cerimoniais (8 de 15), assim como previsto por Cabral (2007) que diz ser essa uma característica comum dos documentos normativos. Isso que indica um grande uso de consequências sociais arbitrárias para manutenção das respostas. $\mathrm{O}$ caráter aversivo dessas consequências é discutível, uma vez que não foram observados e registrados os comportamentos descritos na contingências em sua ocorrência real, mas a presença de consequências arbitrárias caracterizadas pela punição, como por exemplo expulsões, sindicâncias, repetências, entre outras (Apêndice 1), sugere um caráter negativo para o documento, no sentido de que ele prescreve mais respostas que devem ser evitadas, do que comportamentos desejáveis que poderiam ser estimulados. Isso pode parecer contraditório com o número maior de contingências positivas, mas somente porque a definição do termo "contingências positivas" utilizado nesse trabalho se refere à descrição do comportamento, e não sobre o caráter ético/moral desses.

Apesar disso, a contingências tecnológicas, ilustradas nas tabelas 3 e 4, servem como bom exemplo de contingências que articulam respostas com demandas dos estudantes e da própria sociedade, sintetizadas no artigo 62 que se referem à capaci- 
dade dos cursos de graduação de habilitarem os estudantes ao exercício profissional. Quando articulado na contingência da tabela 3, que consiste também numa contingência positiva, esse artigo apresenta uma consequência tecnológica para o cumprimento de uma resposta coerente com missão organizacional da instituição, com clara função social (Artigo 20). Quando articulado na contingência da tabela 3, caracterizada como tecnológica negativa, ela resulta em ambiguidade pela falta de especificidade na resposta exigida.

Os temas identificados (gráfico 1), apesar de parecerem abrangentes em um primeiro momento, se mostram demasiadamente incompletos na medida em que apresentam no máximo 3 contingências cada um e a maioria possui em torno de 2 ou 3 contingências completas. Três dos temas não possuem contingências completas. Portanto, diversos temas foram identificados, mas por conta do baixo número de contingências e maior parte delas serem contingências incompletas, eles se tornam superficiais e muito pouco descritos. A presença de contingências completas em determinado tema, e a falta em outros, também pode indicar uma prioridade da universidade para normatização de um determinado tema, e esse desequilíbrio ilustra também uma dispersão de normas do assunto em outros documentos, com menor valor descritivo, gerando uma possível falta de legislação sobre alguns temas.

A caracterização das contingências não determina, no entanto, o seguimento ou não de regras. Isto é, a regra não pode ser entendida como uma causa do comportamento; seguir regras é um comportamento e, como tal, é aprendido. É pela interação social que o comportar-se por regras se estabelece na história de reforçamento e, como um operante, pode ser modificado (MATOS, 2001). Portanto, características individuais dos sujeitos em um determinado grupo podem fazer variar o seguimento de regras ou não, para além da maneira como essas são formuladas.

\section{Conclusão}

Este trabalho possui diversas limitações como, por exemplo, o número reduzido de contingências relacionadas ao ensino na graduação, o que dificulta que sejam inferidas com precisão informações sobre o planejamento de ensino feito pela universidade. Porém, estima-se que a lógica funcional apresentada para descrição e análise dos dados quantitativos e qualitativos parecem oferecer uma alternativa concreta para avaliação dos propósitos, efetividade e mesmo adequação do regramento escolhido pelas universidades. Também é inviável fazer afirmações completamente precisas sobre características dos documentos analisados, uma vez que o estudo pormenorizado deles foi feito somente de uma parcela específica, $6 \%$ de seu inteiro teor, a julgar pelo número de itens; para isso seria necessário que esta pesquisa tivesse como objetivo a descrição e análise de contingências dos documentos como um todo, e não só sobre ensino na graduação.

Os trabalhos de Cabral (2007), Lourencetti (2015) e Todorov et al (2004), entre outros, indicaram que quando é utilizado um método e modelo teórico da Análise do Comportamento para análise e descrição de textos normativos, o resultado recorrente é o de que esses documentos são pouco descritivos e frequentemente in- 
completos, em larga medida. Embora esta pesquisa tenha investigado somente um aspecto restrito do Estatuto e do Regimento da Unesp, o resultado não foi diferente, o que indica que provavelmente uma análise completa dos documentos, e talvez até de outros textos normativos, também resultem em características semelhantes. Kubo e Botomé (2003) argumentam que essa falta de objetividade na elaboração de diretrizes se sustenta numa concepção comum de que o conhecimento é tratado de maneira subjetiva, o que dificultaria o seguimento da regra.

O trabalho de Dantas e Teixeira Júnior (2014), mais próximo deste, ao analisar algumas regras na Resolução No 214 da Universidade Federal de Mato Grosso do Sul (UFMS) chega a concluir que todos os artigos analisados são incompletos, embora tenham analisado somente 6. Este trabalho inclui também a informação de que a resolução estudada não é bem divulgada no local, sendo um outro fator que explicaria o não seguimento das normas estabelecidas. Em nosso caso também seria importante avaliar o conhecimento das normas que analisamos, pois, a instituição também poderia divulgar e facilitar ainda mais o acesso ao Estatuto e Regimento da Unesp.

O Art. $3^{\circ}$, da Lei de Introdução às Normas do Direito Brasileiro estabelece que "Ninguém se escusa de cumprir a lei alegando que não a conhece." (BRASIL, 1942). Assim como leis de âmbito nacional, estadual e municipal, as leis de instituições da educação podem ser mal formuladas, mal divulgadas e mesmo assim o fato de meramente existirem pode ser argumento para inviabilizar justificativas quanto ao seu não seguimento e justificar aplicação de punições estabelecidas:

"Na perspectiva da Análise do Comportamento, tal postura adotada
por nossos legisladores não favorece com que leis, regimentos ou
resoluções sejam compreendidas e seguidas pelo ouvinte, sem que
cuidados com sua formulação e apresentação sejam tomados. Es-
tudos sobre regras têm apontado diversos fatores que afetam esse
seguimento, comprovados por trabalhos experimentais e teóricos da
área. A elaboração e apresentação de leis e resoluções mais precisas,
com base nos princípios da Análise do Comportamento, podem ser
mais efetivas no estabelecimento e manutenção do comportamento
requerido por elas.”(DANTAS; TEIXEIRA JÚNIOR, 2014, p. 25)

Os resultados desta pesquisa, do mesmo modo como os de outros trabalhos semelhantes, indicam a possibilidade de que esses documentos sejam reformulados de modo a possibilitarem a identificação de contingências completas, com maior proporção de contingências tecnológicas e positivas, como uma maneira de torná-los mais efetivos. No entanto, são conhecidas as implicações éticas de afirmações deste tipo, compreendendo que regras são frequentemente utilizadas para coagir, ao invés de educar, e também são utilizadas para a manutenção da sobrevivência das agências de controle (SKINNER, 1981) em vez da sobrevivência de práticas culturais saudáveis. De forma alguma defendemos que toda e qualquer regra deva ser cumprida, independentemente do seu contexto e acreditamos que análises desse tipo podem, inclusive, instrumentalizar melhor críticas a normas injustas, cuja ambiguidade pode levar, mesmo que inadvertidamente, a se defender um caráter danoso, em vez de justo. 
É necessária, ainda, a realização de novas pesquisas sobre o tema, sobretudo com textos que exibem essas características (contingências completas, tecnológicas, positivas) para verificar se de fato a presença delas resulta em uma maior efetividade das normas. Um documento reescrito dessa maneira poderia oferecer maior clareza ao leitor sobre o que deve ou não deve ser feito diante de determinados contextos e o porquê, visto que a função do comportamento exige que suas consequências sejam identificadas. Acreditamos que tal elaboração venha a ser importante não somente por uma possível efetividade das normas, mas também por razões éticas, garantindo normas mais democráticas que poderiam, inclusive, ser contestadas e criticadas mais diretamente, garantindo maior eficiência à gestão de recursos humanos na universidade, especialmente em relação a direitos e deveres da comunidade, a partir do momento em que se reconhece de maneira mais clara e transparente o planejamento que a instituição educativa utiliza em relação aos estudantes.

\section{Referências}

ALBUQUERQUE, Luiz Carlos de; PARACAMPO, Carla Cristina Paiva. Psicologia USP, v. 21, n. 2, p. 253-273, jun. 2010.

ALBUQUERQUE, Luiz Carlos de; MESCOUTO, Wandria De Andrade; PARACAMPO, Carla Cristina Paiva. Controle por regras: efeitos de perguntas, sugestões e ordens. Acta Comportamentalia, v. 19, n. 1, p. 19-42, 2011.

BAUM, William M. Compreender o Behaviorismo: comportamento, cultura e evolução. 2. ed. Porto Alegre: Artmed, 2006.312 p.

BRASIL. Lei No 4.657, de 4 de Setembro de 1942. Lei de Introdução às normas do Direito Brasileiro. Rio de Janeiro: 1942. Disponível em: <http://www.planalto.gov.br/ccivil_03/decreto -lei/Del4657.htm>. Acesso em: 2 de maio de 2017.

BRASIL. Lei No 9.503, de 27 de Setembro de 1997. Institui o Código de Trânsito Brasileiro. Brasília: 1997. Disponível em: <http://www.planalto.gov.br/ccivil_03/leis/L9503.htm>. Acesso em: 1 de maio de 2017

CABRAL, Cibele Zanirato. Descrição e análise das contingências presentes na proposta de estatuto da pessoa com deficiência. 178 f. Dissertação (Mestrado em Psicologia) - Universidade Estadual Paulista, Bauru, 2007.

DANTAS, Ludmila Zatorre; TEIXEIRA JÚNIOR, Ronaldo Rodrigues. Regras em uma resolução da Universidade Federal de Mato Grosso do Sul e seus efeitos no comportamento de alunos e professores. Universitas: Ciências da Saúde, Brasília, v. 12, n. 1, p. 15-27, jan./jun. 2014.

DITTRICH, Alexandre. Behaviorismo radical, ética e política: aspectos teóricos do compromisso social. 480 f. Tese (Doutorado em Filosofia) - Departamento de Filosofia e Metodologia das Ciências, Universidade Federal de São Carlos, São Carlos, 2004.

DITTRICH, Alexandre. Sobrevivência ou colapso? B. F. Skinner, J. M. Diamond e o destino das culturas. Psicologia: Reflexão e Critica, Porto Alegre, v. 21, n.2, p. 252-260, 2008. Disponível em: <http://dx.doi.org/10.1590/S0102-79722008000200010>. Acesso em: 29 de maio de 2016.

GLENN, Sigrid. S. Metacontingencies in Walden Two. Behavior Analysis and Social Action, v. 5 , ns, p. 2-8, 1986.

KUBO, Olga Mitsue; BOTOMÉ, Silvio Paulo. A transformação do conhecimento em comportamentos profissionais na formação do psicólogo: as possibilidades nas diretrizes curriculares. In: BRANDÂO, M. Z. et al. (Org.). Sobre comportamento e cognição: a história e os avanços, a seleção por consequências em ação. Santo André: ESETec, 2003. v. 11. p. 483-496. 
LOURENCETTI, Luiz Antonio. Descrição e Análise de Contingências Presentes em Legislações Referentes à Mobilidade Urbana. 2015. 196f. Dissertação (Mestrado em Psicologia) - UNESP, Faculdade de Ciências, Bauru, 2015.

MATOS, Maria Amélia. Comportamento governado por regras. Revista Brasileira de Terapia Comportamental e Cognitiva, São Paulo, v. 3, n. 2, p. 51-66, 2001

MOREIRA, Márcio Borges., MEDEIROS, Carlos Augusto. Princípios básicos de análise do comportamento. Porto Alegre: Artmed, 2007.

PARACAMPO, Carla Cristina Paiva; ALBUQUERQUE, Luiz Carlos de. Comportamento controlado por regras: revisão crítica de proposições conceituais e resultados experimentais. Interação em Psicologia, Curitiba, v. 9, n. 2, p. 227-237, 2005.

SIDMAN, Murray. Coerção e suas implicações. Tradução de Maria Amália Andery e Tereza Maria Sério. Campinas: Editora Livro Pleno, 2009. 301 p. (Original em inglês, publicado em 1989).

SKINNER, Burrhus Frederic. Ciência e Comportamento Humano. 11. ed. São Paulo: Martins Fontes, 2003. 489 p. (Original em inglês, publicado em 1953).

SKINNER, Burrhus Frederic. Contingências do Reforço: Uma Análise Teórica. Em: Os pensadores. 2. ed. São Paulo: Abril Cultural, 1984, p. 161-396. (Original em inglês, publicado em 1969).

SKINNER, Burrhus Frederic. Sobre o Behaviorismo. Tradução de Maria da Penha Villalobos. 15. ed. São Paulo: Editora Cultrix, 2009. 216 p. (Original em inglês, publicado em 1974).

SKINNER, Burrhus Frederic. Selection by Consequences. Science, v. 213, n. 4507, p. 501-504, 1981.

SOUZA, Vivian Bonani de; CARRARA, Kester. Delineamentos culturais: transferência de controle de reforçadores arbitrários a naturais e de imediatos a atrasados. Revista Brasileira de Terapia Comportamental e Cognitiva, São Paulo, v. 15, n. 1, p. 83-98, 2013. Disponível em: <http://www.usp.br/rbtcc/index.php/RBTCC/article/view/569/380>. Acesso em: 29 de maio de 2016.

TODOROV, João Claudio; MOREIRA, Maísa.; PRUDÊNCIO, Mara Regine de Andrade; PEREIRA, Gisele Carneiro Campos. O Estatuto da Criança e do Adolescente como metacontingência. In: Maria Zilah da Silva BRANDÃO; Fatima Cristina de Souza CONTE; Fernanda Silva BRANDÃO; Yara Kuperstein INGHBERMAN; Vera Lucia Menezes da SILVA; Simone Martin OLIANE (Org.). Sobre comportamento e cognição: contingências e metacontingências, contextos socioverbais e o comportamento do terapeuta. $1^{\mathrm{a}}$ ed. Santo André: ESETec, Vol. 13, p. $44-51,2004$

TODOROV, João Claudio; MOREIRA, Márcio Borges; MOREIRA, Maísa. Contingências entrelaçadas e contingências não-relacionadas. In: João Claudio TODOROV; Ricardo Corrêa MARTONE; Marcio Borges MOREIRA. Metacontingências: comportamento, cultura e sociedade. Santo André, SP: ESETec. p. 55-59, 2005.

UNESP. Regimento Geral da UNESP. Aprovado pelo decreto no 10.161, de 18 de agosto de 1977. A UNESP rege-se por seu Estatuto e por esse Regimento Geral. São Paulo. 1977. Disponível em: <http://www.fc.unesp.br/Home/Administracao/DivisaoTecnicaAcademica/regimento_geral.pdf $>$. Acesso em: 29 de maio de 2016.

UNESP. Estatuto da UNESP. Resolução UNESP no 21, de 21 de fevereiro de 1989. Disponível em: <http://unesp.br/servico/estatuto_unesp.pdf>. Acesso em: 29 de maio de 2016.

UNESP, Sobre a UNESP - Perfil. Disponível em: <http://www.unesp.br/portal\#!/apresentacao/perfil/>. Acesso em: 28 de maio de 2016. 
* Graduando em Psicologia na Universidade Estadual Paulista Júlio de Mesquita Filho, Bauru, São Paulo, Brasil.

* Graduando em Psicologia na Universidade Estadual Paulista Júlio de Mesquita Filho, Bauru, São Paulo, Brasil.

*** Graduanda em Psicologia na Universidade Estadual Paulista Júlio de Mesquita Filho, Bauru, São Paulo, Brasil

**** Professor ajunto da Universidade Estadual Paulista Júlio de Mesquita Filho, Bauru, São Paulo, Brasil.

\section{Correspondência}

Victor Henrique Souza Cunha - Universidade Estadual Paulista Júlio de Mesquita Filho, Faculdade de Ciências de Bauru. Avenida Engenheiro Luiz Edmundo Carrijo Coube, 14-01. Núcleo Residencial Presidente Geisel. CEP: 17033360. Bauru, São Paulo, Brasil.

E-mail: daktuno@gmail.com - soleil.yang5@gmail.com - janine.coelho.correa@gmail.com - kester@ fc.unesp.br

Recebido em 17 de junho de 2017

Aprovado em 20 de março de 2018 
